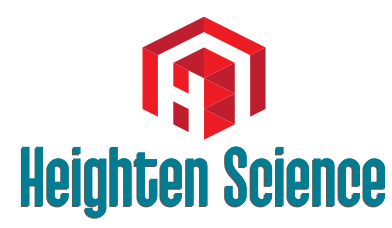

P U B L I C A T I O N S Corporation

\title{
Bilateral Parasymphyseal Osteoma
}

\author{
Akanksha Gupta, Sangeeta Singh Malik, Swati Gupta and Ravi \\ Prakash SM* \\ Department of Oral Medicine and Radiology, Subharti Dental College, Meerut, Uttar Pradesh, \\ India
}

\begin{abstract}
*Address for Correspondence: Ravi Prakash SM, Department of Oral Medicine and Radiology, Subharti Dental College, Meerut, Uttar Pradesh, India, Tel: 08449401654; Email: sasan_ravi@rediffmail.com
\end{abstract}

Submitted: 17 December 2016

Approved: 19 January 2017

Published: 20 January 2017

Copyright: @ 2017 Gupta A, et al. This is an open access article distributed under the Creative Commons Attribution License, which permits unrestricted use, distribution, and reproduction in any medium, provided the original work is properly cited.

Keywords: Bilateral parasymphyseal osteoma; Onion-peel appearance; Periosteal reaction

\section{ABSTRACT}

Osteoma is a benign osteogenic tumor arising from the proliferation of cancellous or compact bone. In the facial bones, both central and peripheral osteomas have been described in the literature. Peripheral type of osteoma is the most common variant in the mandible, which occurs on the cortical bone surface. We present a case of a fourteen year old boy who had swelling on right and left parasymphyseal region. Radiographs revealed radiopacity having onion-peel appearance and histopathology gave the final diagnosis of osteoma. Periosteal reaction giving rise to onion peel appearance on the radiograph has been reported in Ewing sarcoma, Garre's osteomyelitis and infantile cortical hyperostosis in the literature but our case shows that similar appearance can be there in osteoma as well.

\section{INTRODUCTION}

Osteoma can be described as a benign neoplasm in which a tumor is formed by the deposition of compact lamellar cortical or cancellous bone [1]. Craniofacial osteomas occur most frequently in the paranasal sinuses, mandible and maxilla, although cases in other bones and in soft tissues such as muscle have also been reported [2]. Peripheral or periosteal osteomas develop as masses attached to the cortical plates and central osteomas arise from the endosteal bone surfaces. Peripheral type of osteoma is the most common variant in the mandible. The pathogenesis of peripheral osteoma is not yet clear. Some authors classify it as a true neoplasm, while others consider it as a developmental anomaly [3]. Osteomas are mostly asymptomatic but may present as a slow growing mass accompanied by pain over the region of the swelling. Our patient had painless swelling on right and left parasymphyseal region. Radiographs revealed radiopacity having onion-peel appearance in that region, which has been reported in Ewing sarcoma, Garre's osteomyelitis and infantile cortical hyperostosis [4]. But histopathology gave the final diagnosis of osteoma.

\section{CASE REPORT}

A 14 year old male patient came with the chief complaint of painless swelling on left and right side of chin since 2 years. Extra oral examination revealed well defined, oval swellings measuring $\sim 1 \mathrm{~cm}$ in greatest dimension having normal overlying skin on right and left parasymphyseal region. These bony hard, non tender swellings were attached to the inferior border of mandible (Figure 1A,B). Intraoral examination revealed absence of any odontogenic cause of infection. On the basis of history and clinical examination, clinical provisional diagnosis of osteoma of right and left parasymphyseal region was made. The patient was subjected to radiographical examination. Mandibular cross-sectional occlusal radiograph revealed well-defined radiopacities extending from the distal aspect from 43 to mesial aspect of 46 on the right side and from 32 to distal surface of 35 on the left side on the buccal aspect of 
the mandible. Periosteal duplication gave the onion-peel appearance (Figure 2). Cone beam computed tomography revealed well-defined radiodense area extending buccally from the inferior border of the mandible in right and left parasymphyseal region (Figure 3). Excisional biopsy along with surgical curettage for recontouring was done and specimen were sent for histopathologic examination. Histopathology revealed irregular bony trabeculae with osteocytes in lacunae and osteoblastic rimming along with minimal interspersed marrow tissue (Figure 4). The radiographic and histopathologic features gave the final diagnosis of osteoma.

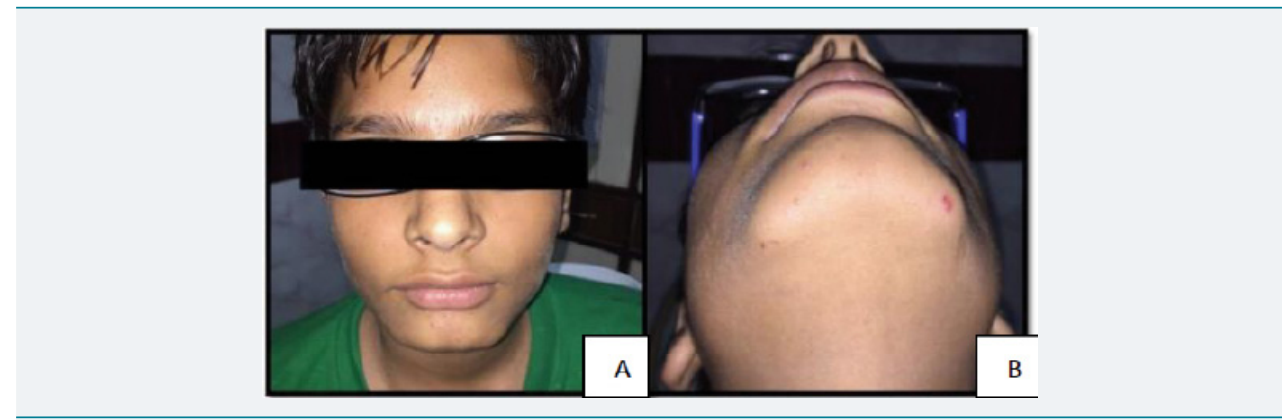

Figure 1: Well defined swellings present in right and left parasymphyseal region.

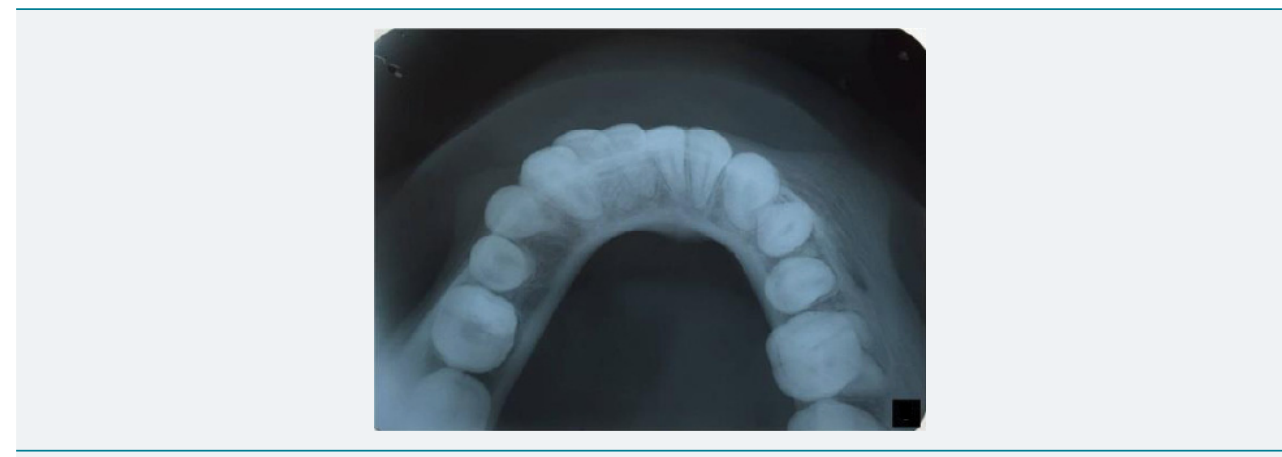

Figure 2: Mandibular cross-sectional radiograph showing radiopacity having onion-peel appearance extending from the distal aspect from 43 to mesial aspect of 46 on the right side and from 32 to distal surface of 35 on the left side on the buccal aspect of the mandible.

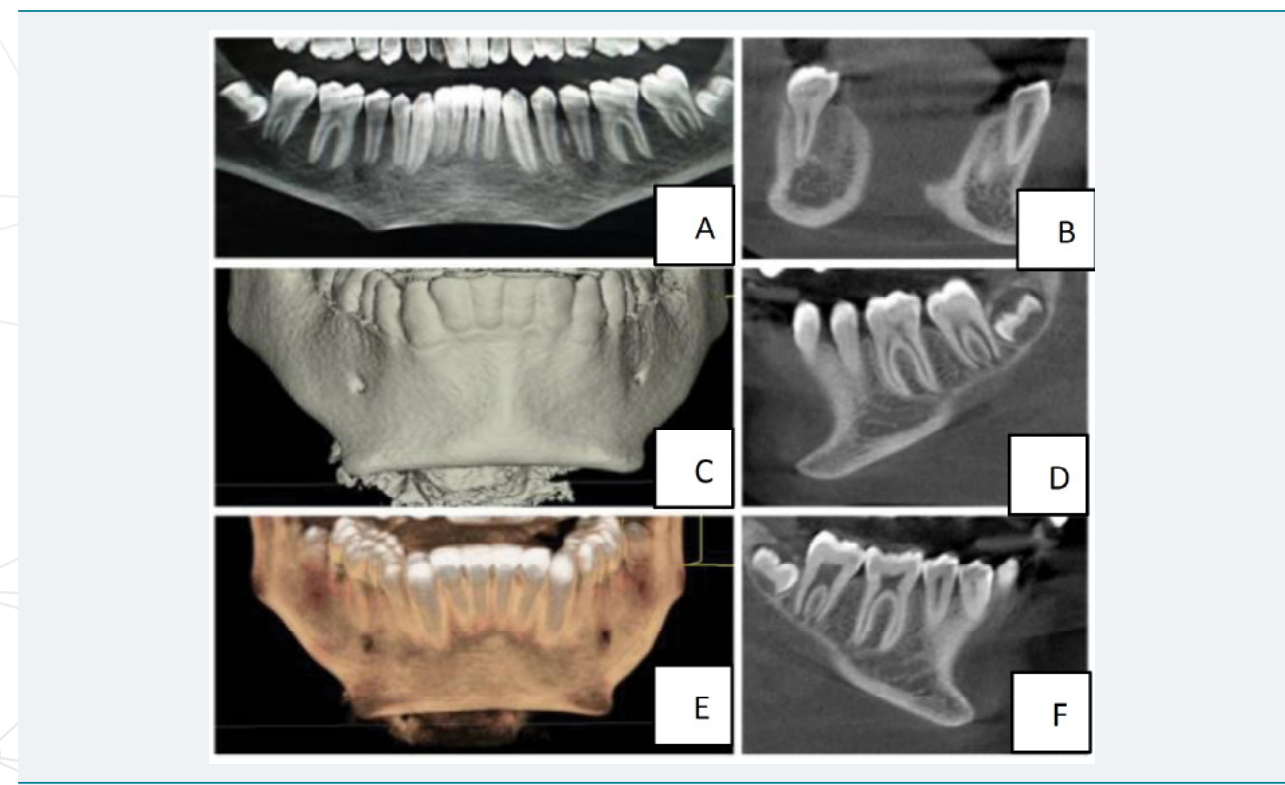

Figure 3: Panoramic, 3-D reconstruction surface mode, 3-D reconstruction volumetric mode, tangential view, left cross-sectional view and right cross-section view respectively of cone beam computed tomography showing well-defined radiodense area extending buccally from the inferior border of the mandible in right and left parasymphyseal region. 


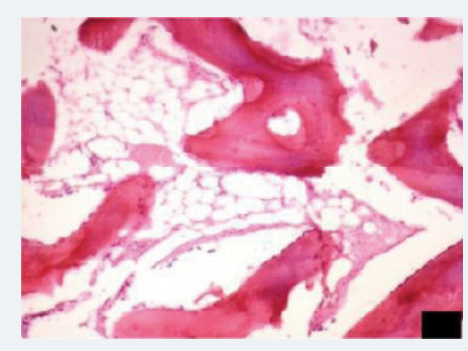

Figure 4: $\mathrm{H} \& \mathrm{E}, 10 \mathrm{x}$ image showing irregular bony trabeculae with osteocytes in lacunae and osteoblastic rimming along with minimal interspersed marrow tissue suggestive of osteoma.

\section{DISCUSSION}

Osteomas of the facial bones are uncommon and only few cases have been reported in the literature. In the maxillofacial area, the most common site is the frontal sinus, followed by the ethmoidal and maxillary sinuses. It has also been reported in the external auditory canal, and rarely in the temporal bone and pterygoid plates $[5,6]$. Peripheral osteoma of the jawbones is quite rare. These lesions usually appear as unilateral, pedunculated mushroom-like masses. In the mandible, the most common sites are the angle and lower border of the body [3,7]. In our patient, osteoma involved parasymphyseal region of right as well as left side. Although the exact etiology and pathogenesis of peripheral osteoma is still debated, yet inflammatory, traumatic, congenital, and endocrine causes have been considered as possible etiologic factors [8].

Generally peripheral osteomas have a very slow growth rate, and most of the times it is asymptomatic. In many cases, its discovery is an incidental finding. However, depending on the location and size, the tumor may cause deformity of the face, deviation of the mandible on opening, exophthalmos or headache [2]. Our patient had painless swellings on parasymphyseal region since two years.

Imaging of osteoma can be done by traditional radiography or by computed tomography (CT). CT scanning with 3-D reconstruction will lead to better resolution and accurate localization [9]. Bone scans can determine the physiologic activity of the peripheral osteoma and evaluate if it is an actively growing young lesion or long standing, mature lesion with no further growth. In our case, radiographs revealed welldefined radiopacities with periosteal duplication giving the onion-peel appearance. Onion-peel appearance has been reported in Ewing sarcoma, Garre's osteomyelitis and infantile cortical hyperostosis in the literature [4]. But our case shows that similar appearance can be there in osteoma as well.

Surgery of osteoma is indicated when the lesion is symptomatic or actively growing. For the mandible there are intraoral or extra oral surgical approaches but intraoral approach is preferable when possible, mainly for cosmetic reasons. Recurrence of osteoma after surgical excision is very rare and malignant transformation has never been reported in the literature [2].

The differential diagnosis may include exostoses, peripheral ossifying fibroma, sessile osteochondroma, osteoid osteoma, periosteal osteoblastoma and paraosteal osteosarcoma. When an exophytic bony growth, firmly attached to the underlying bone is present in the oral cavity, a differential diagnosis should be made between an osteoma or a more common exostosis. One of the major differences of osteoma from other bony exostoses is the ability of this lesion to continue growing during adulthood [2].

Patients with peripheral and endosteal osteomas and supernumerary or impacted teeth, should consider the possibility for Gardner's syndrome $[5,10]$. The triad of 
colorectal polyposis, skeletal abnormalities and multiple impacted or supernumerary teeth is consistent with this syndrome. Patient with mandibular osteoma, suspected to have Gardner's syndrome, should be further examined to rule out colorectal carcinoma as mandibular osteomas may may be a genetic marker for the development of colorectal carcinoma [11].

\section{REFERENCES}

1. Gundewar S, Kothari DS, Mokal NJ, Ghalme A. Osteomas of the craniofacial region: A case series and review of literature. Indian J Plast Surg. 2013; 46: 479-485. Ref.: https://goo.gl/E7XAu7

2. Woldenberg $\mathrm{Y}$, Nash $\mathrm{M}$, Bodner L. Peripheral osteoma of the maxillofacial region. Diagnosis and management: A study of 14 cases. Med Oral Patol Oral Cir Bucal. 2005; 10: E139-142. Ref.: https://goo.gl/EXOCCj

3. Sayan NB, Uçok C, Karasu HA, Gunhan O. Peripheral osteoma of the maxillofacial region: A study of 35 new cases. J Oral Maxillofacial Surg. 2002; 60: 1299-1301. Ref.: https://goo.gl/iiD6u5

4. Singh D, Subramaniam P, Bhayya PD. Periostitis ossificans (Garre's osteomyelitis): An unusual case. J Indian Soc Pedod Prev Dent. 2015; 33: 344-346. Ref.: https://goo.gl/kmXX1L

5. Lew D, DeWitt A, Hicks RJ, Cavalcanti MG. Osteomas of the condyle associated with Gardner's syndrome causing limited mandibular movement. J Oral Maxillofac Surg. 1999; 57: 1004-1009. Ref.: https://goo.gl/ltV1lr

6. Batsakis JG. Tumors of the Head and Neck: Clinical and Pathological Consideration $2^{\text {nd }}$ edn. Baltimore, MD: Williams\&Wilkins 1979; 405-406.

7. Kaplan I, Calderon S, Buchner A. Peripheral osteoma of the mandible: a study of 10 new case and analysis of the literature. J Oral Maxillofac Surg. 1994; 52: 467-470. Ref.: https://goo.gl/92TDSR

8. Lucas RB. Pathology of tumors of the Oral Tissues. Edinburgh, Scotland: Churchill Livingstone. 1984; 191-194.

9. Bodner L, Bar-Ziv J, Kaffe I. CT of cystic jaw lesions. J Comput Assist Tomogr. 1994; 18: 22-26. Ref.: https://goo.gl/cSyE6t

10. Wesley RK, Cullen CL, Bloom WS. Gardner's syndrome with bilateral osteomas of coronoid process resulting in limited opening. Pediatr Dent. 1987; 9: 53-57. Ref.: https://goo.gl/dHo4yL

11. Sondergaard JO, Rusmussen MS, Videbaek H, Bernstein IT, Myrhoj T, et al. Mandibular osteomas in sporadic colorectal carcinoma. A genetic marker. Scand J Gastroenterol. 1993; 28: 23-24. Ref.: https://goo.gl/8WqYdy 